
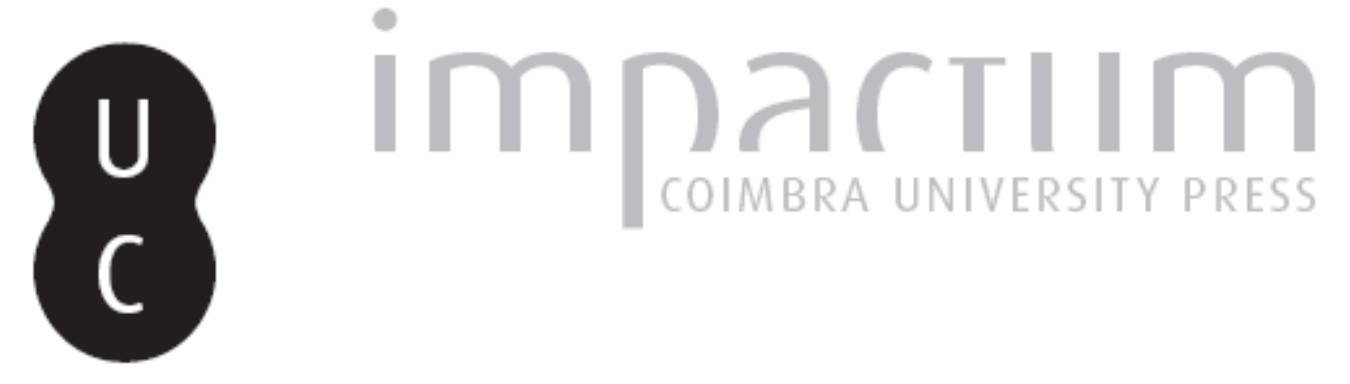

\title{
Os rivais do político verdadeiro: homens, animais e monstros. Contributos d'o político e d'a república para o retrato dos falsos políticos
}

\author{
Autor(es): $\quad$ Soares, Carmen
}

Publicado por: Centro de História da Universidade de Lisboa

URL

persistente:

URI:http://hdl.handle.net/10316.2/23750

DOI:

DOI:http://dx.doi.org/10.14195/0871-9527_20_21

Accessed : $\quad$ 26-Apr-2023 14:26:15

A navegação consulta e descarregamento dos títulos inseridos nas Bibliotecas Digitais UC Digitalis, UC Pombalina e UC Impactum, pressupõem a aceitação plena e sem reservas dos Termos e Condições de Uso destas Bibliotecas Digitais, disponíveis em https://digitalis.uc.pt/pt-pt/termos.

Conforme exposto nos referidos Termos e Condições de Uso, o descarregamento de títulos de acesso restrito requer uma licença válida de autorização devendo o utilizador aceder ao(s) documento(s) a partir de um endereço de IP da instituição detentora da supramencionada licença.

Ao utilizador é apenas permitido o descarregamento para uso pessoal, pelo que o emprego do(s) título(s) descarregado(s) para outro fim, designadamente comercial, carece de autorização do respetivo autor ou editor da obra.

Na medida em que todas as obras da UC Digitalis se encontram protegidas pelo Código do Direito de Autor e Direitos Conexos e demais legislação aplicável, toda a cópia, parcial ou total, deste documento, nos casos em que é legalmente admitida, deverá conter ou fazer-se acompanhar por este aviso.

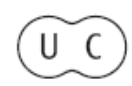




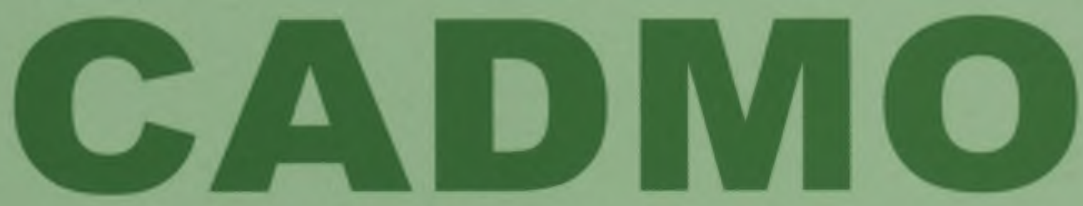

Revista de História Antiga

\author{
Centro de História \\ da Universidade de Lisboa
}

\title{
20
}

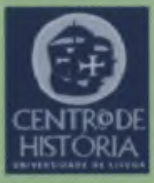

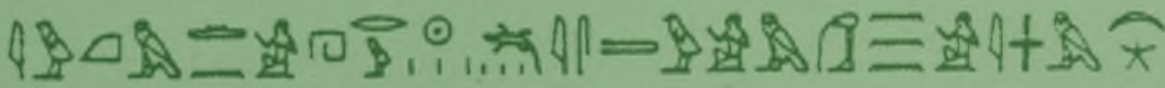

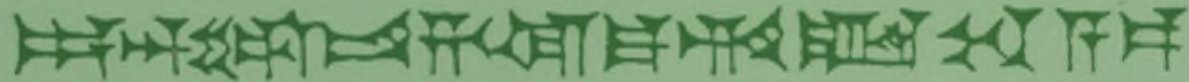

MHNIN AEI $\Delta$ E $\Theta E A ~ \Pi H \Lambda H I A \triangle E \Omega$ 


\title{
OS RIVAIS DO POLÍTICO VERDADEIRO: HOMENS, ANIMAIS E MONSTROS. CONTRIBUTOS D'O POLÍTICO E D'A REPÚBLICA PARA O RETRATO DOS FALSOS POLÍTICOS
}

\author{
CARMEN SOARES \\ Universidade de Coimbra \\ cilsoares@gmail.com
}

O tema que elegi para reflexão subverte deliberadamente a tradicional leitura que sobre filosofia política têm suscitado $O$ Político e A República de Platão, no que à figura do governante diz respeito(1). Ou seja, não busco as características e predicados do rei ou político

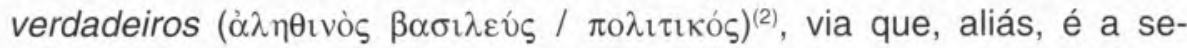
guida pelas personagens dos diálogos platónicos em apreço(3), mas procurarei colocar em evidência o que em ambos os textos são meios para atingir esse fim. Assim, procurarei, antes, averiguar como são caracterizadas as figuras que no panorama político da época ocupavam cargos de gestão dos interesses da pólis, a quem vulgarmente se poderia atribuir o epíteto de políticos, mas que, como se demons-

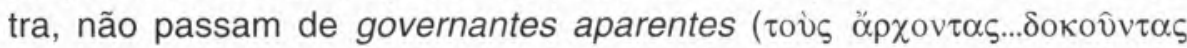
uóvov, Pol. 293 c 7-8). Não se trata, no entanto, de inverter as linhas de pensamento postuladas n'O Político e nos livros VIII e IX d'A República, orientadas para a definição do retrato completo do político

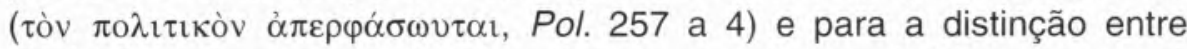

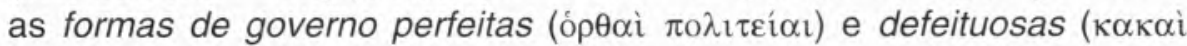
$\left.\pi \circ \lambda_{1} \tau \varepsilon i \alpha_{1}\right)$, bem como respectivas almas dos seus governantes, pois são estas que determinam as formas daquelas ${ }^{(4)}$. O que proponho é, ao invés, tentar compreender em que medida esses indivíduos a 
quem a sociedade reconhece o direito de exercer a governação merecem, da parte de Platão, formas de tratamento que ultrapassam a simples denúncia de fraquezas, para resvalar em ataques acérrimos e insultuosos contra a sua própria condição humana.

Abordar de maneira tão directa uma temática de implicações cívicas evidentes, como é a denúncia dos falsos políticos e a busca do seu representante verdadeiro, evidencia não apenas a díade essencial do pensamento do filósofo (ser/parecer), mas também a consciência de que a missão da filosofia é conduzir o homem à felicidade ${ }^{(5)}$. E esta, para o homem que vive na pólis, atinge-se quando se realizar a constituição perfeita, forma de governo que só está ao alcance daquele

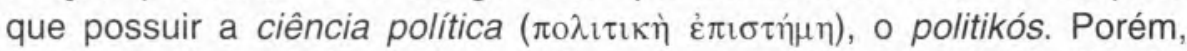
conforme têm enfatizado os estudos sobre a construção da identidade, todo o processo de identificação radica numa dinâmica dialógica de confronto do "eu» com o "outro". Não é, portanto, de estranhar que Platão, para chegar ao retrato do político, i.e., para dizer o que ele é, recorra à apresentação do que ele não é. E é aqui que se desenham perfis diversos e de conotação ética variável, podendo as personagens dos textos limitar-se a emitir informações neutras ou apoiar-se noutras fortemente carregadas de sentido pejorativo. Foi a constatação de que esses pseudo-políticos podem ser apresentados de tão distintas formas que me levou a identificá-los com três grupos de indivíduos, elencados numa sucessão que revela um percurso do racional (o Homem) para o irracional (os animais) e o selvagem (os monstros). Aliás, esta sequência foi-me sugerida pelo próprio texto d'O Político, conforme passarei a evidenciar.

A primeira via seguida pelas personagens para individualizar o político/rei conduziu à sua identificação com o rei-pastor ${ }^{(6)}$. Porém, semelhante conclusão levantou, de imediato, a dificuldade de haver outros

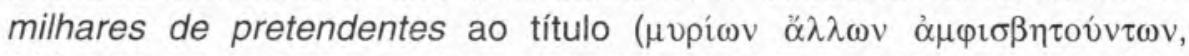
268 c 3), uma vez que muitos profissionais podem reclamar-se especialistas da ciência da criação colectiva de seres humanos ( $\dot{\alpha} v \theta \rho \omega ́ \pi \omega v$

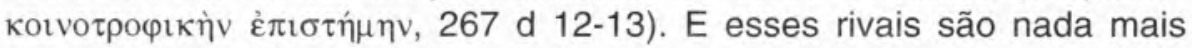
do que mercadores, lavradores, padeiros, mestres de ginástica e médicos. Face ao resultado insatisfatório desta investigação, os interlocutores enveredam por uma outra via, a do mito, também ela inconclusiva e a suscitar nova pesquisa, desta feita baseada no paradigma da tecelagem. É precisamente a propósito da aplicação da distinção entre o tecelão/arte de tecer e os profissionais/artes auxiliares da tecelagem ao objecto de pesquisa do diálogo (o político e a ciência política) 


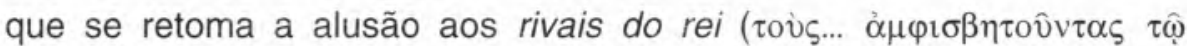
$\beta \alpha \sigma \imath \lambda \varepsilon \hat{\imath}, 289$ c 5-6). Neste passo percebe-se, através da identificação destes indivíduos com categorias sociais subordinadas - os escravos

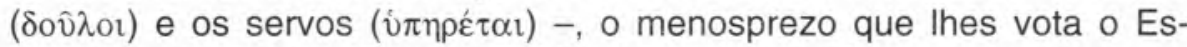
trangeiro, porta-voz do autor ${ }^{(7)}$. No entanto, logo de seguida, o mestre confessa ao seu discípulo, Sócrates-o-Moço, que esta interpretação estava errada. Tal como é típico da árdua caminhada dialéctica em busca da verdade, feita de sucessivos enganos e correcções, é preciso obter uma análise mais segura ( $\beta \varepsilon \beta \alpha$ ó $\varepsilon \varepsilon \rho o v, 289$ d 5).

$\mathrm{Na}$ sequência desta reponderação, são liminarmente afastados da condição de rivais do político (òv $\alpha \mu \varphi \imath \sigma \beta \eta \tau \eta \dot{\tau} \omega \varsigma, 289$ e 1), os homens de condição não livre. Também entre os que gozam de liberdade, mas que exercem negócios por conta de outrem - como são os cambistas, os mercadores, os armadores e os revendedores - também esses servos não rivalizam ( $\dot{\alpha} \mu \beta \iota \sigma \beta \mu \tau \eta \dot{\sigma o v \sigma \imath,} 290$ a 2) todos com a politikê epistême. Neste momento, Platão lança um ataque directo ao regime da sua pólis, quando exclui, de forma categórica, da basilikê epistême, para além dos thêtas (a mais humilde mão de obra contratada), os assalariados ( $\mu 1 \sigma \theta \omega \tau$ ov́s, 290 a 4). Como se sabe, entre estes últimos incluíam-se os cidadãos que, em inícios do séc. IV, recebiam um misthos pelo exercício de quase todos os cargos políticos (exceptuam-se os Estrategos e provavelmente os membros do Areópago) ${ }^{(8)}$. Ou seja, começa-se, desde já, a questionar a concepção corrente segundo a qual quem exercesse o poder político deveria ser o primeiro (se não o único) a merecer o epíteto de especialista da política

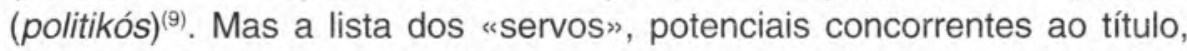
inclui ainda outros profissionais, cujas competências lhes conferiam um inegável ascendente entre os cidadãos comuns: os arautos, os escribas e os secretários das diversas magistraturas do regime democrático ateniense. Adiantando uma conclusão que Ihe parece óbvia, Sócrates-o-Moço afirma que todos aqueles indivíduos até aí conside-

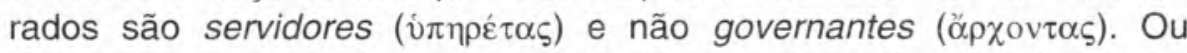
seja, parece que a via proposta pelo Estrangeiro - de encontrar entre

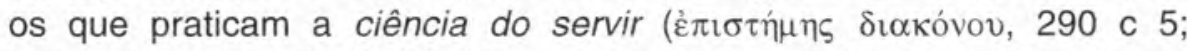

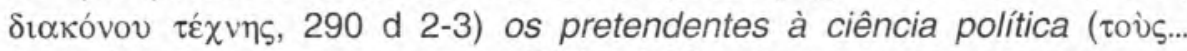

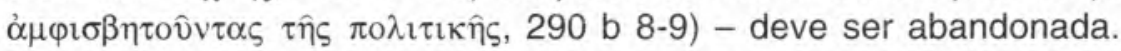

O papel de um mestre consiste em conduzir o aprendiz ao conhecimento e, como esclarece mais adiante (291 b 7), é do desconheci-

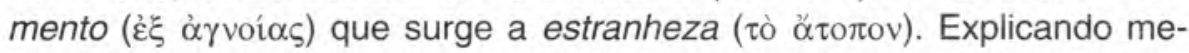

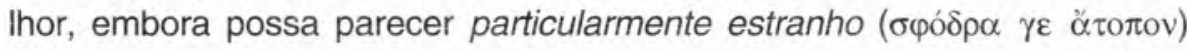


ao jovem interlocutor que se busque numa parcela do grupo dos servos os indivíduos que reclamam possuir a ciência política, essa é a verdadeira pista (íxvovs, 290 d 5) para tal demanda. A parcela a que se refere inclui os servos dos deuses, i.e., dois especialistas

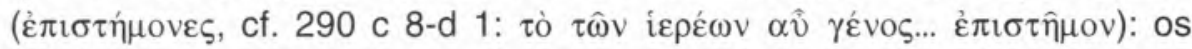
adivinhos e os sacerdotes. $O$ enorme prestígio das suas funções conferia-Ihes uma reputação intocável e ajudava a compreender o orgulho que os dominava. Aliás, as constituições de muitas das cidades gregas haviam encontrado uma maneira de associar esse poder que vinha da proximidade com o divino ao poder político. Platão está a referir-se à mais distinta das magistraturas do sistema democrático, o arconterei (290 e 3-8). Está, assim, encontrada a primeira categoria de rivais do político: indivíduos com actividades implicadas na gestão da coisa pública ( $\tau \dot{\alpha} \tau \hat{\omega} v \pi_{0} \lambda \varepsilon \omega v \pi \rho \alpha ́ \gamma \mu \alpha \tau \alpha, 291$ c 1). Mais adiante, depois de

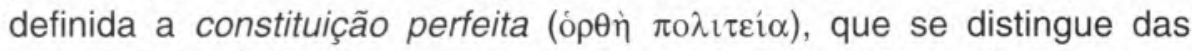

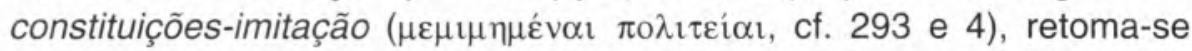
o elenco dos profissionais que, por confundirem as suas ciências (militar, jurídica e retórica) - auxiliares da politikê epistême - com a do verdadeiro político, vivem na ilusão de serem políticos (303 e-305 c). Mas, antes disso, somos confrontados com uma categoria distinta de pseudo-políticos, a que se não atribui qualquer ciência específica (como fora o caso dos generais, dos juizes e dos oradores) ou função de prestígio (conforme sucedera com os adivinhos e os sacerdotes) ${ }^{(10)}$.

Pois bem, é quando passa a considerar essa trupe de indivíduos que ronda os negócios públicos (

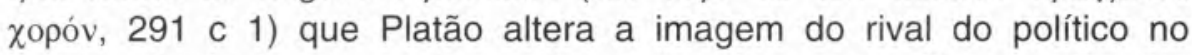
sentido do fantástico e da bestialização. De novo utiliza o adjectivo atopos ("estranho»), agora para qualificar essa raça multiforme ( $\pi \alpha ́ \mu \phi v \lambda o ́ v ~ \tau \imath ~ \gamma \varepsilon ́ v o \varsigma)$, evocada através do recurso a metáforas de animais selvagens e monstros. Embora reconheça, juntamente com Luc Brisson e Jean François Pradeau ${ }^{(11)}$, não ser possível estabelecer com toda a certeza qual a razão e o objectivo que levaram o filósofo a recorrer a semelhantes comparações, estas interessam-me sobretudo enquanto verdadeiro leit-motiv da sua obra. Aliás, Christopher Rowe, estabelecendo um paralelo entre a galeria do bestiário d'O Político e a variedade de políticos descrita n'A República (livros VIII-IX), propõe que a cada uma das espécies daquele diálogo corresponde um dos caracteres dos governantes deste. A saber: os leões representariam os timocratas, os centauros os oligarcas, os sátiros e os animais sem força, mas astutos e com capacidades mutantes, como seriam os 
camaleões, os democratas, indivíduos por norma propensos a alterar a sua opinião(12). $\mathrm{O}$ insulto final à horda irracional dos falsos políticos surge imediatamente a seguir à revelação do estado de estupefacção (novo emprego duplo do adjectivo átopos, 291 b 6, 7) do Estrangeiro. O chorós da gente conotada com as feras e monstros vem agora

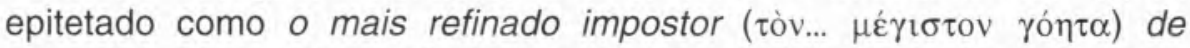
entre o universo dos sofistas e o mais experimentado dos indivíduos nessa arte (i. e., na retórica sofística) ${ }^{(13)}$. Daqui até $303 \mathrm{c}$, o Estrangeiro procura demonstrar que nenhuma das constituições existentes corresponde à orthê politeia, logo não é possível encontrar o alethinós basileús/politikós. Pior ainda, todos os indivíduos que participem como governantes em qualquer dos regimes identificados (monarquia, tirania, aristocracia, oligarquia e democracia), se não forem sábios, i.e., não possuírem conhecimento,

devem ser repudiados, sob a alegação de não serem verdadeiros polí-

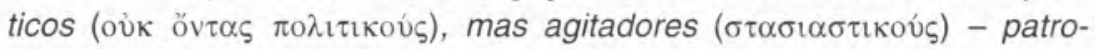

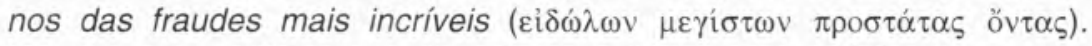
Tal é o seu carácter que de actores e impostores exímios ( $\mu \varepsilon \gamma i \sigma \tau o v \varsigma$

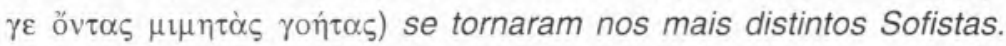

(303 c 1-5)

Em suma, tal como as coisas do mundo sensível se distinguem das ideias do universo inteligível, também um sofista, enquanto simulacro de quem detém o saber, corresponde a uma imitação do político autêntico, mas não pode, de modo algum, ser confundido com este.

Mas voltemos às metáforas de animais e monstros. Também n' $A$ República deparamos com a comparação de um governante (o tirano) a um animal selvagem (o lobo). Para sermos mais precisos, este lobo partilha com os seres fantásticos d'O Político a dimensão mítica, uma vez que se evoca a lenda da transmutação de Licáon, rei lendário da Arcádia, após o sacrifício do próprio filho a Zeus. O paralelo com o tirano baseia-se no facto de, tal como um pai que de protector se transforma em carrasco (Licáon), também o tirano chega ao poder para bem do povo, mas rapidamente mata e condena ao exílio a gente

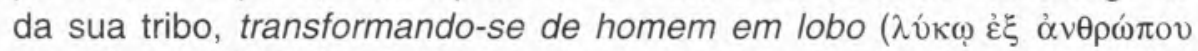
$\gamma \varepsilon v \varepsilon \dot{\sigma} \theta \alpha \mathrm{l}, 566$ a 4). Repare-se que o retrato deste rival do político comporta uma carga pejorativa mais carregada do que qualquer imagem de leão, centauro ou sátiro. Já não é só a dimensão selvagem e irracional que se enfatiza, nem apenas o aspecto fantástico, ligado ao 
hibridismo das formas das figuras mitológicas, mas sobretudo a faceta monstruosa, i. e., contrária às regras mais elementares da vida civilizada. Esse lobo, como referimos, devora os seus semelhantes e familiares, ou seja, pratica o canibalismo. A razão para que alguns indivíduos incorram em tamanha transgressão radica, conforme se depreende, na configuração da alma ${ }^{(14)}$.

A psychê é formada por três partes: uma dotada de razão

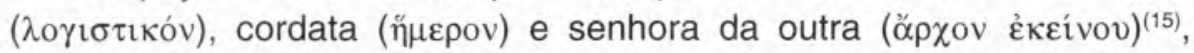
responsável pelo pensar (439 a) e pelo aprender (436 a, 580 d, 581 b),

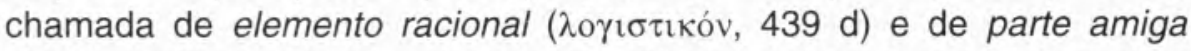

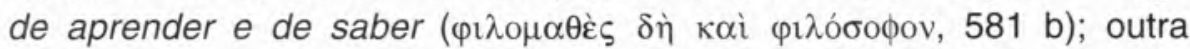
animal $(\theta \eta \rho \hat{\omega} \delta \varepsilon \varsigma)$ e selvagem ( $\left.\alpha \gamma_{\rho} \imath \mathrm{ov}\right)^{(16)}$, o desejo, chamado de con-

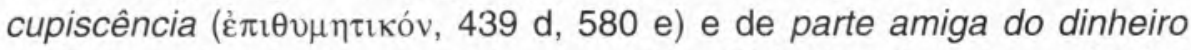

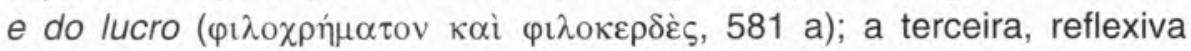

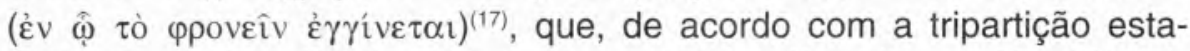

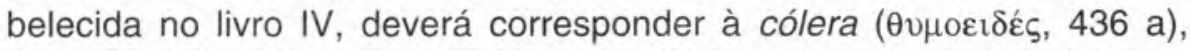
parte também chamada de amiga da vitória e das honrarias ( $\phi \imath \lambda$ óvıкov

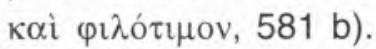

Os sonhos traduzem o domínio que cada uma das partes pode ter sobre as outras. Assim, quando a parte animal e selvagem controla as outras, a alma agita-se no sono, perturbada pelos piores e mais despudorados crimes (incesto, sexo - com seres humanos, deuses e animais -, homicídios e canibalismo, 571 c-d). Ao invés, quando a parte animal e a racional não estão em conflito, a terceira entra em acção, contexto propício a atingir a verdade ( $\tau \hat{\eta} \varsigma \dot{\alpha} \lambda \eta \theta \varepsilon i ́ \eta \varsigma)$ e menos

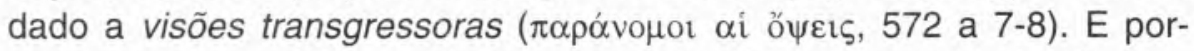
que, quando se fala de visões, se pressupõe a necessidade de imagens, é disso mesmo que nos vai falar o texto d' $A$ República ao

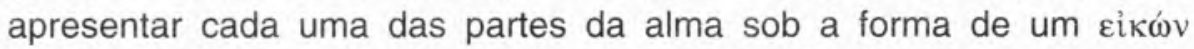
(588 b-589 d). Os três ícones propostos são de dimensões diversas, surgindo do maior para o mais pequeno, a saber: um com forma de

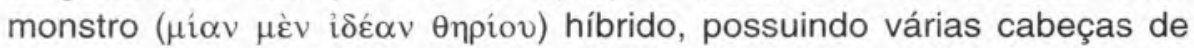
animais selvagens e domésticos, dispostas a toda a volta do corpo, e com potencialidades metamórficas (tipo Quimera, Cila e Cérbero) - este é o ícone maior e materializaria a parte da alma animal e selvagem;

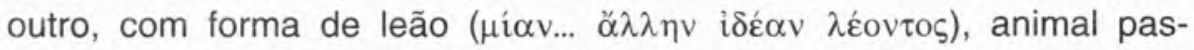
sível de ser domado, corresponderia à parte reflexiva; finalmente, o mais pequeno deve ser moldado com a forma humana ( $\mu$ í $\alpha \nu$ $\delta \grave{\varepsilon}$

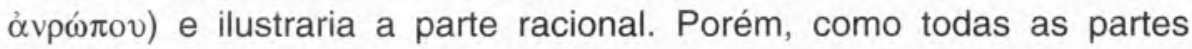


juntas formam a alma, para dar essa aparência externa de unicidade, as três imagens devem ser envolvidas por um invólucro também ele de forma humana. Os indivíduos em cujas almas as partes personificadas nos seres monstruosos e no leão dominam o homem, i. e., a razão, esses cometem actos injustos. Já as pessoas honestas são aquelas em que o homem interior tem o máximo domínio sobre o seu

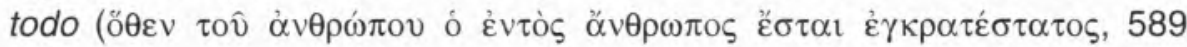
a 7- b1), o que se verifica quando o homem subjuga o monstro, tendo por aliado o leão. O objectivo dessa parte (o pequeno homem ou a razão) reside em tornar a psychê harmoniosa no seu todo, o que consegue ao fazer com que todas as partes sejam amigas ${ }^{(18)}$. Como escreveu Platão a propósito das funções do elemento racional da alma, cabe-lhe a ela governar toda a alma, pois preocupa-se não só com os seus interesses pessoais (como fazem as outras duas partes), mas cuida do interesse geral (441 e, $442 \mathrm{c}$ ).

Sublinhe-se que n'O Político, qual verdadeiro motivo recorrente no discurso de Platão, voltamos a encontrar esta mesma associação

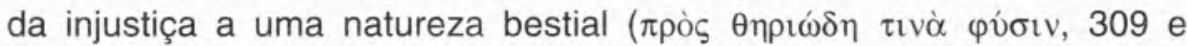
3). Semelhante noção surge já para o final do diálogo (309 d 10-e 5), a propósito da distinção entre as pessoas de espírito voluntarioso

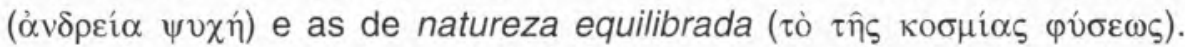
Segundo o Estrangeiro, um indivíduo de carácter ousado, que não participe da justiça, incorre na chamada theriôdes physis.

Desta aproximação do texto d'O Político à República, podemos inferir como apelidar os falsos políticos de leões, centauros, sátiros e toda a espécie de monstros multiformes constitui uma denúncia de que toda essa trupe de politiqueiros são pessoas desonestas. Como se lê n'A República, é quando a parte selvagem das almas escraviza a domesticada que estamos perante a desonestidade (589 d 2-3).

Podemos, pois, concluir que, entre o universo dos rivais do político verdadeiro, é possível hierarquizar os indivíduos com base na apreciação que sobre eles tecem as personagens d'O Político. No topo da pirâmide encontram-se os que participam das artes auxiliares da ciência política (militares, juízes e oradores), seguem-se o arconterei e seus servidores (arautos, escribas e secretários) e na base surgem todos aqueles que não detêm qualquer saber, mas arvoram possuí-lo, pelo que merecem o cognome insultuoso de "Sofistas"! 


\section{Notas}

(1) Cita-se as traduções de SOARES 2008 e ROCHA PEREIRA ${ }^{10} 2007$.

(2) A noção "verdadeiro" vem expressa no original tanto pelo recurso ao adjectivo $\alpha \lambda \eta \theta$ เvos

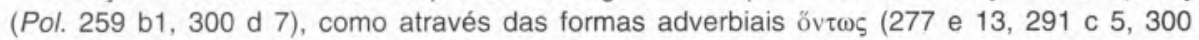
c 9-10) e $\dot{\alpha} \lambda \eta \theta \hat{\omega} \varsigma$ (293 c 7).

(3) N'O Político (260 d 11-e 9), a personagem principal do diálogo afirma claramente que o

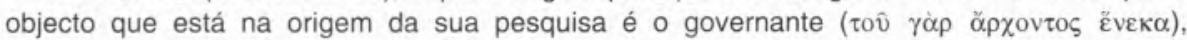

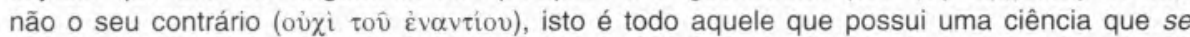
aparenta com a daquele (

(4) Como se lê em A República, 445 c 9-10: há tantas formas específicas de constituições, quantas podem ser as almas; e em 545 d 1-2: toda a constituição muda por virtude daquele mesmo que detém o poder.

(5) LUC BRISSON e JEAN-FRANÇOIS PRADEAU (2003: 14) chamaram a atenção para a utilidade cívica da filosofia na sua introdução à tradução francesa d'O Político.

(6) À excepção dos passos em que se reporta ao governante do regime monárquico, enquanto figura distinta dos senhores do poder das outras constituições (oligarquia, democracia e tirania), o substantivo "rei" e a expressão "ciência/arte do rei" são sinónimos de "político" e de "ciência/arte política". Ao que sugere o conjunto do texto, esta equivalência deverá explicar-se pelo facto de a monarquia e o rei verdadeiros constituírem as realizações perfeitas do político e do regime que ele dirige.

(7) Ao considerarmos que, no presente caso, o pensamento da personagem principal se identifica com o de Platão, estamos a colocar-nos na esteira da interpretação de KRAUT (1992: 27-30), para quem a personagem central serve de veículo para contrariar ou defender determinadas conclusões, por meio de determinados argumentos, segundo faria o próprio filósofo.

(8) Sobre o papel da mistoforia, instituída por Péricles, no regime democrático de Atenas, veja-se FERREIRA (1990: 83-87).

(9) Conforme indica o sufixo - iko -, usado na formação do adjectivo politikós, o politikós anêr é o homem que possui determinado saber específico, aquilo que se costuma chamar uma "ciência" (epistême) ou "arte" (techne).

(10) No comentário ao passo em apreço, BRISSON e PRADEAU assinalam essa distinção em duas categorias de rivais do político (2003: 250, n. 262).

(11) BRISSON et PRADEAU (2003: 250, n. 266).

(12) Cf. ROWE (1995: com. ad loc.).

(13) Vd. 291 с 3-4.

(14) Sobre a questão, veja-se, entre outros, os estudos de ANNAS (1981: 109-152), THYSSEN (1998) e REEVE (1988: 118-169).

(15) Vd. 571 c 4-5.

(16) Vd. 571 c 5.

(17) Vd. 572 a 7.

(18) Leia-se WHITE (1979: 234-235). 


\section{Bibliografia}

J. ANNAS (1981), An Introduction to Plato's Republic. Oxford University Press, Oxford.

L. BRISSON et J.-F. PRADEAU (2003), Platon. Le Politique. GF Flammarion, Paris.

J. R. FERREIRA (1990), A democracia na Grécia Antiga. Livraria Minerva, Coimbra.

R. H. KRAUT (1992), The Cambridge Companion to Plato. Cambridge University Press, Cambridge.

C. D. C. REEVE (1988), Philosopher-kings. The Argument of Plato's Republic. Princetown University Press, Princetown, New Jersey.

M. H. ROCHA PEREIRA (102007), Platão, A República. Introdução, tradução e notas. Fundação Calouste Gulbenkian, Lisboa.

$\mathrm{CH}$. ROWE (1995), Plato. Statesman. Edited with an Introduction, Translation \& Commentary. Aris \& Phillips, Warminster.

C. SOARES (2008), Platão. O Político. Tradução do grego, introdução e notas. Círculo de Leitores, Lisboa.

H. P. THYSSEN (1998), "The Socratic paradoxes and the tripartite soul", in E. N. Ostenfeld (ed.), Essays on Plato's Republic. Aarhus University Press, Aarhus, 59 72.

N. P. WHITE (1979), A Companion to Plato's Republic. Blackwell, Oxford. 